\title{
ガスクロマトグラフィーによる食品中総臭素の定量
}

(昭和 59 年 7 月 19 日受理)

\author{
小山田則孝* 上野 清 一* \\ 久保田かはる*石崎睦雄*
}

\section{Determination of Total Bromine in Foods by Gas Chromatography}

\author{
Noritaka Oyamada, Seiichi Ugno, Kaoru Kubota and Mutsuo IshizakI \\ (Department of Environmental Health, Ibaraki Hygienic Laboratory: \\ 4-1, Atago-cho, Mito, Ibaraki, Japan)
}

\begin{abstract}
An improved method for the determination of total bromide in foods was established.
A sample of $1 \mathrm{~g}$ was taken into an alumina ceramic crucible and $1.5 \mathrm{ml}$ of alkaline monoethanolamine solution was added. The sample was ashed at $550^{\circ} \mathrm{C}$ for $8 \mathrm{hr}$ and the ashed residue was dissolved in $0.1 \mathrm{~N}$ sodium hydroxide solution and distilled water. The sample solution was transferred to the reaction vessel, then $0.3 \mathrm{~g}$ of manganese dioxide and $10 \mathrm{ml}$ of $50 \%$ sulfuric acid were added, and the reaction vessel was connected to the absorption vessel containing $2 \mathrm{ml}$ of $4 \times 10^{-3} M$ styrene monomer ethanol solution and 15 $\mathrm{ml}$ of $30 \%$ potassium chloride solution. Bromine produced was expelled to the reaction vessel by bubbling nitrogen gas (flow rate, $100 \mathrm{ml} / \mathrm{min}$ ) through the sample solution for 9 min, and then the liberated bromine was reacted with styrene monomer. The product (bromo derivative of styrene) was extracted with $n$-hexane and determined by ECD-GC.

In this method, it was found that bromide in foods could be determined with a recovery of $84-91 \%$ and a variation coefficient of $4.6-8.9 \%$. The detection limit was $0.1 \mu \mathrm{g} / \mathrm{g}$.
\end{abstract}

(Received July 19, 1984)

Key words: 臭菜 bromine; 食品 foods; スチレンブロム誘導体 styrene bromo derivative; ガ スクロマトグラフィー (ECD) gas chromatography (ECD)

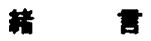

近年食品中以残留する臭素が注目されてきている。食 品中の総臭菜の剆定法としてガスクロマトクラフ法、ヨ

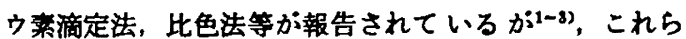

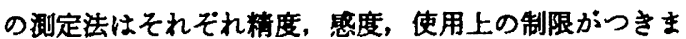
とうことなどの難点がある.これらのらち我が国ではフ ルオレセインを発色試桼として用いた比色法を基とした 分析法が広く利用されている. しかしながらこの方法て は，呈色時に共存する他のハロダン化合物の影敏を受け たり，呈色が安定しないことなどから，しばしばその測 定值が大きく变動し，测定困難な例が生じる场合があ る. また操作過程で酸化郕として重クロム酸塩を用いれ ばならないことから，実倹後これらの廃液処理に問題を 牫している.

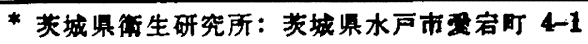

そこで著者らは，硫酸酸性下桌素イオンが二酸化マン ガンで定昷的に酸化されて臭慗となることに着目じ， 発生した奥来をスチレンモノマーと反応させれば，先に 著者らが報告した奄子捕獾型 (ECD) 検出ガスクロマト クラフィー (GC) による具素酸〉 と同様に，食品中の総 臭莱をスチレンブム誘道体として简単に測定可能であ ろらと考え，この方法を利用した分析法を娭討し，筬便 かつ精度の高い分析法を確立したので報告する.

实卧方法

1. 证料

生産者から直接戝入したもの及び水戸市内で戝入した

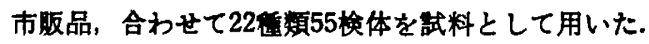

2. 试 菲

臭菜イオン標準溶液：臭化カリウム $0.149 \mathrm{~g}$ を精科し て, 水に溶かして $100 \mathrm{ml}$ とした $\left(\mathrm{Br}^{-}\right.$として 1,000 $\mathrm{ppm}$ 含む)るのを用時通宜希积して用いた。 
(A)

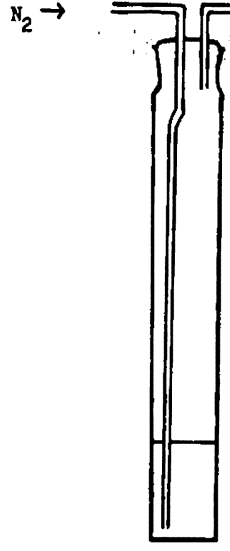

(c)

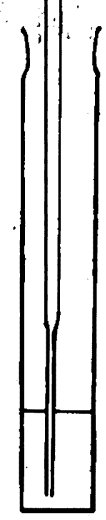

(B)
Fig. 1. Apparatus for generation and absorp. tion of bromine

(A), reaction vessel $(2.4 \mathrm{~cm} \times 19.5 \mathrm{~cm}$, T19); (B), absorption vessel $(2.5 \mathrm{~cm} \times$ $20 \mathrm{~cm}$, T 19/18); (C), teflon tubing $(6 \mathrm{~mm}$ $\times 4.5 \mathrm{~cm}$ )

モノェタノールアミンーフルカリ溶液：上村6 ${ }^{6} ら の$ 方法 により，用時調製した。

$4 \times 10^{-8} M$ スチレンモノマー溶液：和光純薬工莱(株) 製特級品を用時 $1 \%$ 水酸化ナトリウム溶液で洗浄し，つ いで水で 2 回洗浄後, 無水酼酸ナトリウムで脱水したも の $42 \mathrm{mg}$ をとり、エタノール $5 \mathrm{ml}$ に溶かし水を加え て $100 \mathrm{ml}$ とした,
Table 1. Operating Conditions of Gas-liquid Chromatograph

\begin{tabular}{ll}
\hline Instrument & $\begin{array}{l}\text { Hitachi 073 type equipped } \\
\text { with ECD }\end{array}$ \\
Column & Glass column $2 \mathrm{~m} \times 3 \mathrm{~mm}$ \\
Liquid phase & $\begin{array}{l}\text { Fluoxylate-K, } 0.5 \% \\
\text { (Uniport } \mathrm{HP}, 80-100 \text { mesh) }\end{array}$ \\
Detector temperature & $300^{\circ} \mathrm{C}$ \\
Column temperature & $130^{\circ} \mathrm{C}$ \\
Carrier gas & $\mathrm{N}_{2}, 60 \mathrm{ml} / \mathrm{min}$ \\
\hline
\end{tabular}

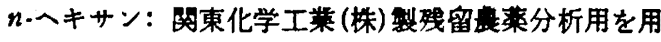
いた.

その他の試菜は市販特狳品を用いた。

3.

臭莱発生装胃を Fig. 1 に示した.

るつぼ:フルミナセラミックス製, 容 $30 \mathrm{ml}$ のもの を用いた。

ガスクロマトグラフ及び GC 用充てん阂は既報に落 じて行い，その条件を Table 1 に示した.

4. 城料の戻化

よく粉砕した武料 $1 \mathrm{~g}$ をアルミナセラミックス䌘るつ 注に科取し、モノエタノールアミンーアルカリ容液 1.5 $\mathrm{ml}$ を加えて混和した後，ホットブレート上で蒸発鞋固 した. ついで $550^{\circ}$ の電気妒で 8 時间灰化した。灰化物 を $0.1 \mathrm{~N}$ 水酸化ナトリウム溶夜 $2.5 \mathrm{ml}$ に溶かした後反 応容器に移した. 同様の操作を繰り返し行った後，皮 3 $\mathrm{ml}$ を用いて,るつぼを洗い洗液を反庍容器へ移し，この あのに二酸化マンガン $0.3 \mathrm{~g}$ を加え正化液とした。

Sample $(1.0 \mathrm{~g})$

add $1.5 \mathrm{ml}$ of alkaline-ethanolamine solution

( $3 \mathrm{ml}$ of monoethanolamine and $0.6 \mathrm{~g}$ of $\mathrm{NaOH}$ in $76 \mathrm{ml}$ of ethanol) ash for $8 \mathrm{hr}$ at $550^{\circ}$

Ashed residue

rinse the crucible twice with $2.5 \mathrm{ml}$ of $0.1 \mathrm{~N} \mathrm{NaOH}$, and with $3 \mathrm{ml}$ of $\mathrm{H}_{2} \mathrm{O}$ transfer into the reaction vessel containing $300 \mathrm{mg}$ of $\mathrm{MnO}_{2}$

Ashed solution

add $10 \mathrm{ml}$ of $50 \% \mathrm{H}_{2} \mathrm{SO}_{4}$

connect the reaction vessel to the absorption vessel containing

$2 \mathrm{ml}$ of $4 \times 10^{-8} \mathrm{M}$ styrene monomer ethanol solution and $15 \mathrm{ml}$ of $30 \% \mathrm{KCl}$ bubble $\mathrm{N}_{2}$-gas (flow rate, $100 \mathrm{ml} / \mathrm{min}$ ) for $9 \mathrm{~min}$

Absorbed solution

extract the solution in the absorption vessel with $2 \mathrm{ml}$ of $n$-hexane

$n \cdot$ Hexane

1

ECD-GC

$\therefore \quad$ Scheme 1. Analytical procedure for bromide in foods 


\section{5. 其稀の定策法}

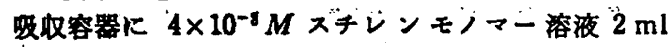
及び $30 \%$ 㙁化カリウム容液 $15 \mathrm{ml}$ を入れた後，4の项

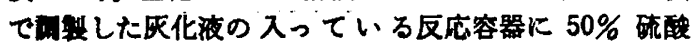
$10 \mathrm{ml}$ を加え，ただちに通気管を装觢し，反応温度 $25^{\circ}$,

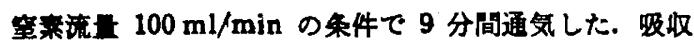
容器の通気管を $30 \%$ 㙁化カリウム湾液 $1 \mathrm{ml}$ で2 回洗 浄し，洗液を吸収容器に移した後， $n$ :ヘキサン $2 \mathrm{ml}$ を

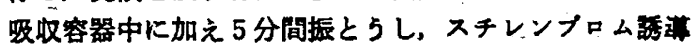
体を抽出した. ついでn-ヘキサン展を分取し，無水硫酸

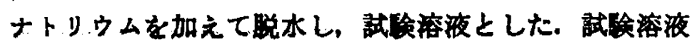
$1 \mu 1$ を ECD-GC K晎し, Table 1 の年件で $\mathrm{Br}^{-}$を测 定した。同様の操作てょり半值幅法を用いて作成した 且線から臭来算出した。武辁操作の概略を Scheme 1 に示した.

\section{结果及び者案}

系秦の吸収剤として、既報と同様にスチレンモノマー を用い，臭来を定量的に発生させる至高条件について検 討した。

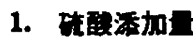

莫案を発生させるために戻化液を酸性にする必要があ ろ. そこで反応温度 $25^{\circ}$ とし，二破化マンガン $0.5 \mathrm{~g}$, 公 素通気量 $200 \mathrm{ml} / \mathrm{min}$ 及び通気時間10分間に設定し，水 $8 \mathrm{ml}$ に臭素イオン票準溶液 $1 \mu \mathrm{g}$ を加えた反応容器に $50 \%$ 硫酸の旦を 6〜12 $\mathrm{ml}$ まで变化させ 5 の定量法に

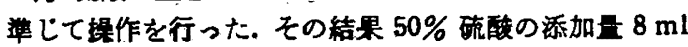
以上で一定・最高の値を示したので，以後の操作では $50 \%$ 硫酸 $10 \mathrm{ml}$ を用いることとした。

2. 酸化成

兵素イオンを酸化して遊離臭素とするため, 酸化剂と

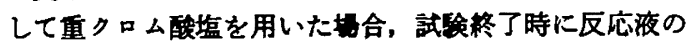
処理に問題が残る.そこで酸化剂として二酸化マンガン を用いて，系素イオンの至音酸化条件について検討し た. 莫茅イオン標潐溶液 $1 \mu \mathrm{g}$ を含む反応容器に二酸化

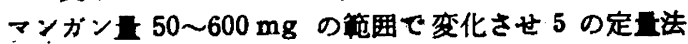

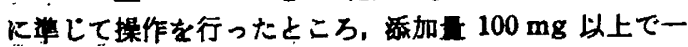
定・取高の值を示したので、二酸化マンガン添加昷は $300 \mathrm{mg}$ とした.

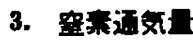

発生させた臭絜を分崔することなく，反応容器中でス チレンモノマーと反応させたところ、ガスクロマトクラ ム上に多数のピークが出現し，しかる定量的にスチレン

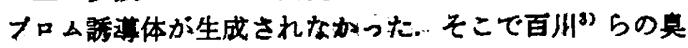

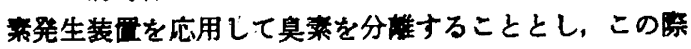
の本法での至適窒菜通気量を求めることとした．筀莱通

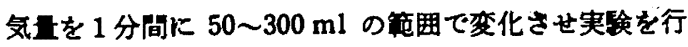
ったところ, Fig. 2 K示したように通気量 $50 \sim 200 \mathrm{ml}$ の箅国で一定・最高の值が得られたので，以後の操作で は筀莱通気是を $100 \mathrm{ml} / \mathrm{min}$ とした。

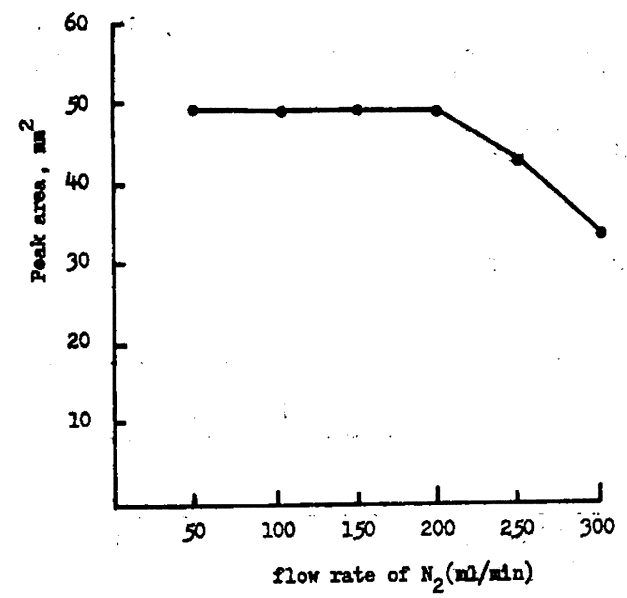

Fig. 2. Relationship between flow rate of $\mathrm{N}_{2}$ gas and the yield of styrene bromo deri. vative

One microgram $\mathrm{Br}^{-}$was used.

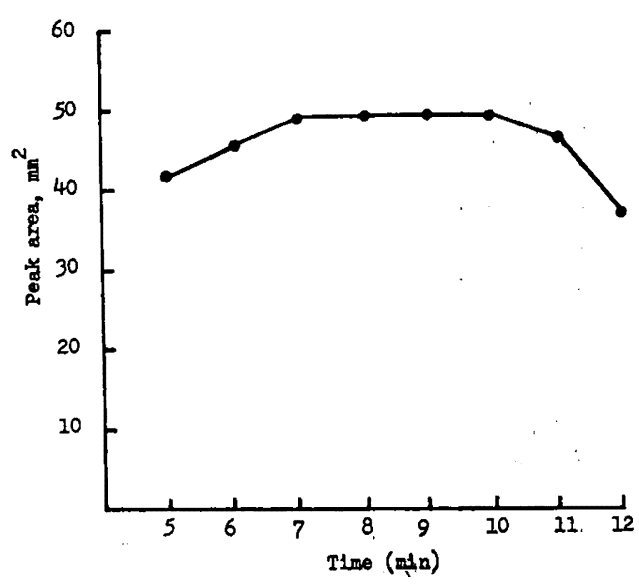

Fig. 3. Relationship between bubbling time and the yield of styrene bromo deriva. tive

Flow rate of $\mathrm{N}_{2}$ gas, $100 \mathrm{ml} / \mathrm{min}$.

\section{4. 通父時间}

公莱通気量 $100 \mathrm{ml} / \mathrm{min}$ とし，通気時間を 5 12 分 间まで変化させ実倹を行ったところ，Fig. 3 に示したよ らに通気時間 7〜10 分間で一定・滞高の值が得られた のた，荎英通気時间を 9 分间とした.

\section{5. 反応温度}

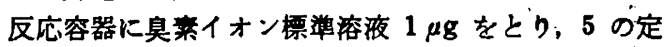

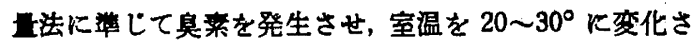

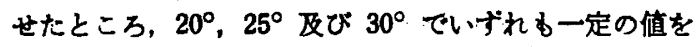
示したので，反応温度を $25^{\circ}$ とした。

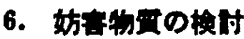

灰化液中に他のハロゲンイオンが共存した坦合, 臭菜イ 
Table 2. Recovery Test of the Proposed Method

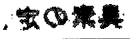

\begin{tabular}{ccccccc}
\hline Sample $(1.0 \mathrm{~g})$ & $\begin{array}{c}\text { Br- added } \\
(\mu \mathrm{g})\end{array}$ & Found $(\mu \mathrm{g})$ & $\begin{array}{c}\text { Mean } \\
(\mu \mathrm{g})\end{array}$ & $\begin{array}{c}\text { Recovery } \\
(\%)\end{array}$ & $\begin{array}{c}\text { C.V. } \\
(\%)\end{array}$ \\
\hline Milled rice & 0 & $0.20,0.20,0.23,0.23,0.19$ & $\mathbf{0 . 2 1}$ & 8.9 \\
& 0.5 & $0.59,0.65,0.66,0.61,0.62$ & 0.63 & 84.0 & 4.6 \\
& 1.0 & $1.09,1.01,0.99,1.20,1.07$ & 1.07 & 86.0 & 7.7 \\
Rice flower & 0 & 2.43 & $2.10,2.58,2.31,2.37$ & 2.36 & & 7.4 \\
(Joshinko) & 1.0 & $3.45,3.20,2.90,3.16,3.50$ & 3.24 & 88.0 & 7.5 \\
& 3.0 & $5.30,5.10,5.05,4.72,5.30$ & 5.09 & 91.0 & 4.7 \\
\hline
\end{tabular}

Table 3. Determination of Total Bromide in Foods

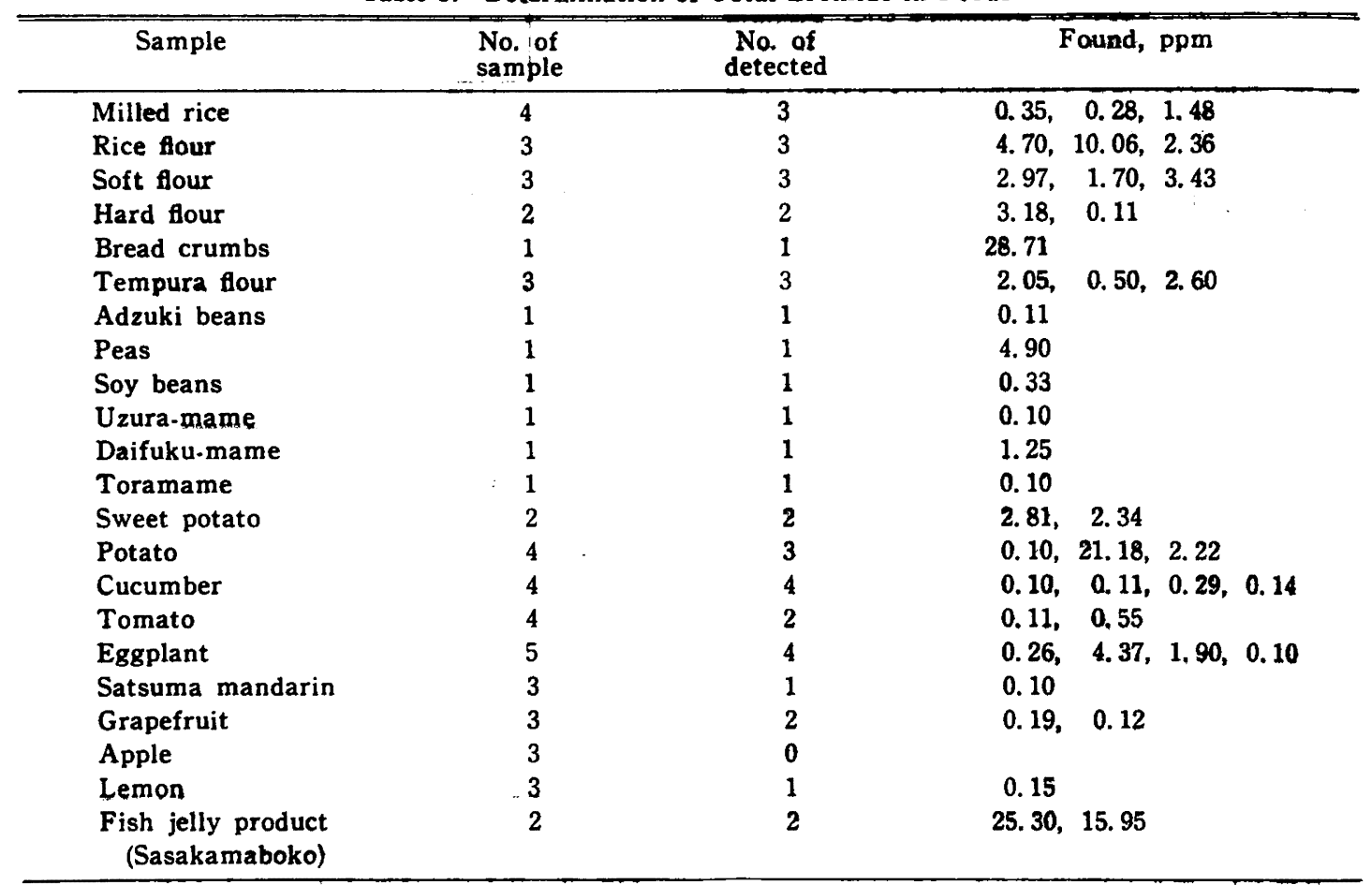

オンと同時に遊倠状焦となりスチレンモノマーと反応す ると考えられる.そこで场丵イオン（㙁化ナトリウム） として $30 \mathrm{mg}$, フッ莱イオン（フッ化カリウム）として $0.5 \mathrm{mg}$ ，ヨウ莱イオン（ヨウ化カリウム）として $0.1 \mathrm{mg}$ をそれぞれ反応容器にとり，定目法に沙じて㩧作を行っ た. その結果クロマトクラム上には, スチレンブムム 落体（保持時間 3分）に一致するピークはなく，本法で は共存する他のハロゲンイオンの影置はないるのと孝え られる.

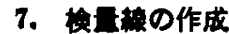

怡卫線埧菜イオンとして各々0.1 $\mu \mathrm{g} / \mathrm{ml}$ から 5.0 $\mu \mathrm{g} / \mathrm{ml}$ の篹网で作成し，以後の定是操作に利用した。

\section{8. 添加回收究期}

米及び上新粉を用いて具莱イオンの源加回収实笑を行 った結果を Table 2 に示した，回収率 84〜91\%，变韧
保数 4.6 8.9\% と良好な結果が得られ，さらに本法で は $1 \mathrm{~g}$ の試料を用いた抲合 $0.1 \mu \mathrm{g}$ まで即定できること

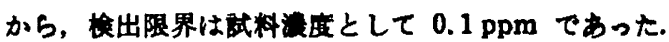

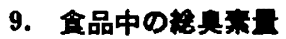

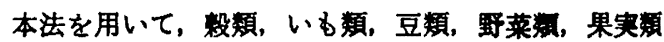

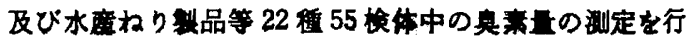
い, その結果を Table 3 に示した。 真来は55伶体中 42

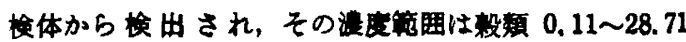

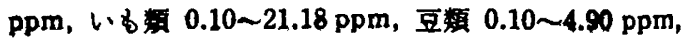

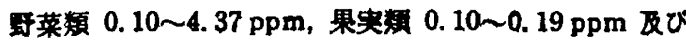

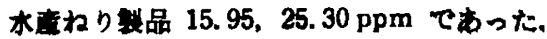

要的

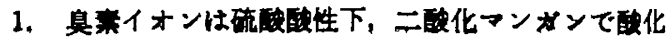

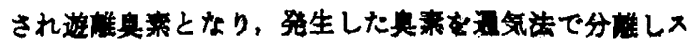
チレンモノマーと反広させることて定早的にスチレンフ 


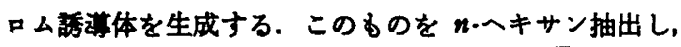

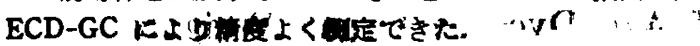

2. 灰化試料を少量化をせるらとができ，质化特間を 短籍させることができた.

3. 米及び上新粉を用いた添加回収実倹では回収率 84〜91\%，変轩保数 4.6〜8.9\%，試料 $1 \mathrm{~g}$ を用いた場 合検出限界は $0.1 \mathrm{ppm}$ と良好な結果が得られた。

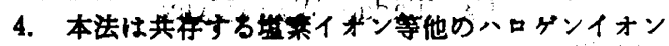
の影すなく简便かつ棈度よく莫妾イオンを湖定でき た.

以上のことから，本法は金品中総基秦の分析法として 十分実用に供し得るるのと考えられる.

女

1) Thewlis, B. H.: J. Sci. Food Agric. 28, 85
88 (1977).

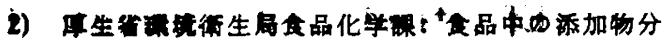

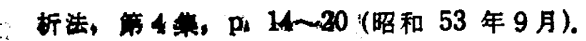

3）百川摆, 山田わ加, 佐藤文子, 堺 敬一：令街 22, 531 535 (1981).

4)而木践司：“定性分析化学” p. 235 236 (1964) 南江些.

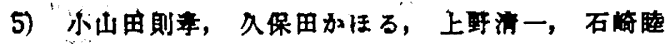
婎：食御誌，24，563～568 (1983).

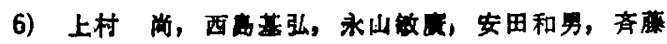

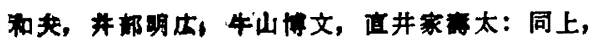
21, 214 218 (1980). 